\title{
Queer avant la lettre: modae performance de gênero nos autorretratos de Claude Cahun
}

Queer avant la lettre: fashion and gender performance in Claude Cahun's self-portraits

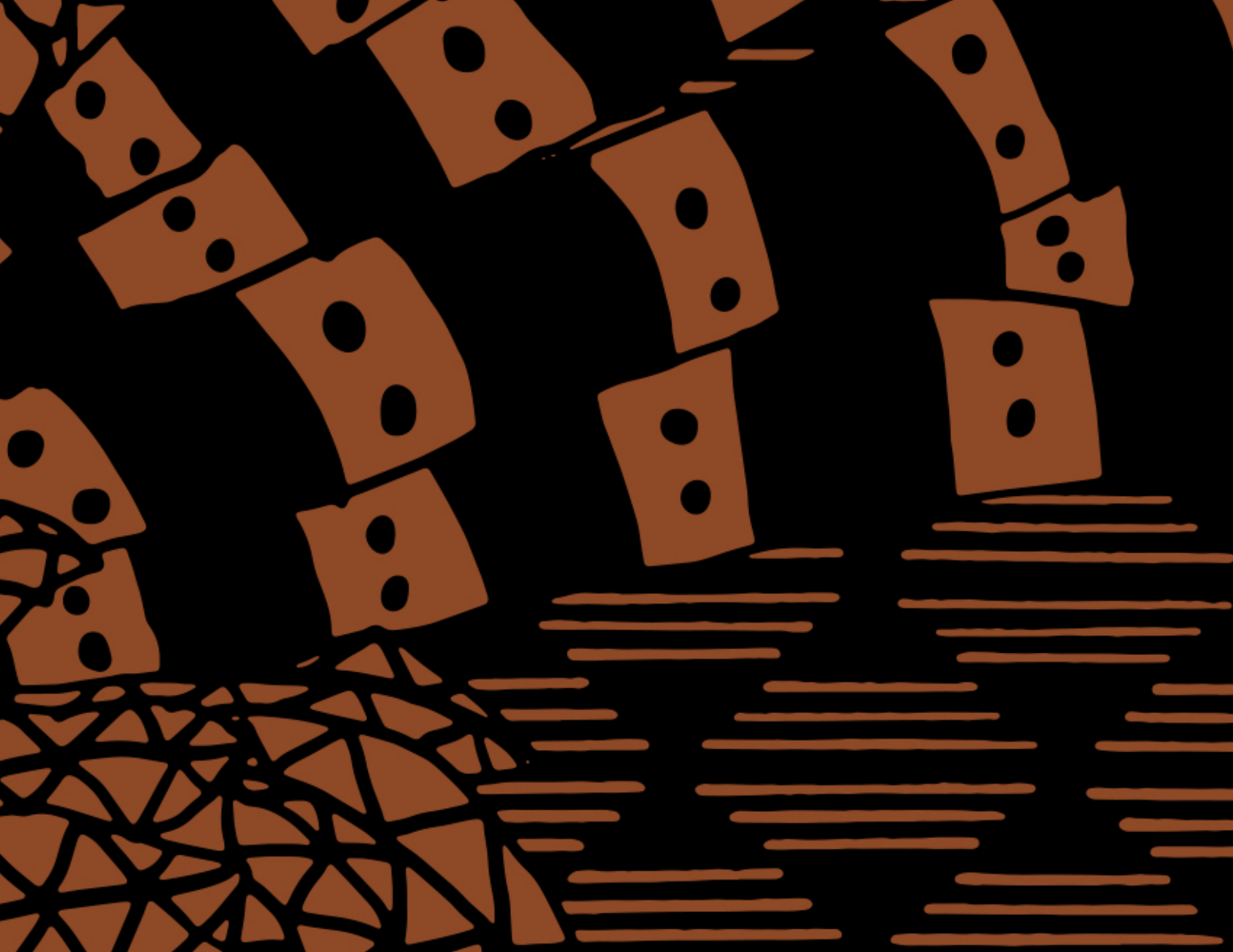

dObras | VOLUME 12 | NÚMERO 27 | SETEMBRO-DEZEMBRO 2019 https://dobras.emnuvens.com.br/dobras / e-ISSN 2358-0003 


\author{
Emerson Silva Meneses ${ }^{1}$ \\ ORCID: https://orcid.org/0000-0002-1788-5111 \\ Martin Jayo \\ ORCID: https://orcid.org/0000-0002-0241-9687
}

[resumo] 0 objetivo do artigo é analisar o uso de vestimentas e demais itens de moda nos autorretratos da fotógrafa francesa Claude Cahun (1894-1954), focando a sua função nas performances de gênero apresentadas nas imagens. Para tanto, procedemos a análise de três fotografias, com base no método iconográfico de Erwin Panofsky. A análise nos permite concluir que a vestimenta (juntamente com outros itens de moda) é um elemento crucial de inteligibilidade das imagens, servindo como um instrumento para o reconhecimento de identidades de gênero. A relevância do trabalho decorre do reconhecimento que Cahun tem recebido ultimamente como precursora das discussões contemporâneas de gênero, bem como da falta de trabalhos que tenham analisado sua obra especificamente na área de Moda.

[palavras-chave] Gênero. Performatividade. Não binariedade. Fotografia.

[abstract] This paper aims to analyze the use of clothing and other fashion items in the self-portraits of French photographer Claude Cahun (1894-1954), focusing on the role they play in the gender performances presented in the images. In order to do so, we proceed to the analysis of three photographs, based on Erwin Panofsky's iconographic method. The analysis leads us to conclude that clothing (alongside with other fashion items) is a crucial element for the intelligibility of the images, serving as a tool for the recognition of gender identities. The relevance of the article stems from Cahun's recent recognition as a precursor to gender discussions, as well as from the lack of research on her work, specifically in the Fashion area.

[keywords] Gender. Performativity. Non-binarity. Photography.

Recebido em: 17-05-2019.

Aprovado em: 28-10-2019.

\footnotetext{
${ }^{1}$ Mestre em Ciências pelo Programa de Pós-Graduação em Têxtil e Moda da Escola de Artes, Ciências e Humanidades da Universidade de São Paulo (EACH-USP). Doutorando pelo Programa de Pós-Graduação em Mudança Social e Participação Política da mesma instituição. emer.meneses@gmail.com. http://lattes. cnpq.br/1427007709160950.

2 Doutor em Administração pela Escola de Administração de Empresas de São Paulo da Fundação Getulio Vargas (EAESP-FGV). Professor da Escola de Artes, Ciências e Humanidades da Universidade de São Paulo (EACH-USP). martin.jayo@usp.br. http://lattes.cnpq.br/9105014250584354.
} 


\section{Introdução}

Claude Cahun (1894-1954) foi uma fotógrafa, escultora, escritora e jornalista francesa. Seu nome de registro era Lucie Renée Mathilde Schwob, mas ela adotou, aos 22 anos de idade, na vida pessoal e artística, o nome Claude, que se caracteriza pela ambiguidade ao poder ser usado, em francês, tanto por homens como por mulheres. Embora costumasse apresentar-se como escritora, é como fotógrafa que ela é mais reconhecida. Seu principal trabalho fotográfico consiste em uma extensa série de autorretratos, produzida ao longo dos anos, em que a artista assumiu uma grande variedade de "personas", cuja característica comum é um desvencilhamento de comportamentos binários de gênero.

Por meio dessas imagens, a artista expõe a (des)construção de sua própria subjetividade. 0 trabalho artístico parece ter-lhe servido como uma ferramenta para o autoconhecimento. De acordo com François Leperlier (2006), seu principal biógrafo ${ }^{3}$, por meio dos autorretratos ela manifestou seu desejo de reinventar-se, repelindo comportamentos e rótulos de gênero. Podemos imaginar que Claude Cahun foi o que denominamos hoje de pessoa trans não binária, e que suas imagens refletem o processo de busca por seu próprio gênero.

Sob essas conjecturas, este artigo visa examinar o uso de roupas e demais itens de moda nos autorretratos de Claude Cahun a fim de responder que papel eles desempenham nas performances de gênero presentes nas imagens. Do ponto de vista metodológico, além da pesquisa bibliográfica, baseamos-nos na análise de três autorretratos da artista que fazem parte do acervo da Jersey Heritage, disponível para consulta on-line ${ }^{4}$. A leitura de duas obras literárias semiautobiográficas da artista - Héroïnes, de 1925, e Aveux non avenues, de 1930 - também contribuiu para a análise ${ }^{5}$.

0 artigo se organiza em três seções principais, além desta introdução e das considerações finais. Na seção 1, reunimos alguns dados biográficos da artista que consideramos relevantes para contextualizar a análise. Na seção 2, referimo-nos à leitura que vem sendo feita recentemente de Claude Cahun como artista que antecipou certos tópicos das discussões de gênero travadas na contemporaneidade. A seção 3 contém a análise propriamente dita, inspirada no método iconográfico proposto por Panofsky ([1955] 2011).

\footnotetext{
3 Escritor e historiador da arte francês, François Leperlier é considerado o "descobridor" da obra de Claude Cahun, no fim da década de 1980, e autor da primeira biografia publicada sobre a artista (LEPERLIER, 2006). Mais recentemente, com o crescente reconhecimento da obra de Cahun, surgiu uma segunda obra biográfica, de autoria da pesquisadora norte-americana Jennifer L. Shaw (SHAW, 2017).

4 Jersey Heritage é uma instituição responsável pela gestão dos principais sítios históricos, museus e arquivos públicos da Ilha de Jersey, onde a artista viveu entre 1937 e 1954. A coleção de autorretratos, adquirida pela instituição na década de 1990, está disponível para consulta em http://www.jerseyheritage.org/collection-items/claude-cahun .

Ambos os livros, hoje em dia, são difíceis de encontrar em suas versões originais. Para Héroïnes, há uma edição recente traduzida para o português (Heroínas. Tradução Daniel Lühmann. Rio de Janeiro: A Bolha Editora, 2016). No caso de Aveux non avenues, tivemos acesso à versão em inglês (Disavowals or cancelled confessions. Tradução Susan de Muth. Cambridge: The MIT Press, 2007).
} 


\section{Quem é Claude: traços biográficos}

Cahun é, antes de tudo, uma artista que revela muito do seu mundo interior em suas fotografias e seus textos. Para seu biógrafo (LEPERLIER, 2006), por meio de sua obra ela manifestava o desejo de se reinventar e, nessa reinvenção, o questionamento de pressupostos identitários de gênero ocupa um papel central.

"Fotografar é apropriar-se da coisa fotografada. Significa pôr a si mesmo em determinada relação com o mundo, semelhante ao conhecimento - e, portanto, ao poder", afirma Susan Sontag ([1977] 2004, p. 14). Nesse sentido, as fotos de Cahun revelam muito: refletem uma metamorfose interior da artista na busca por seu próprio gênero (LEPERLIER, 2006). Por meio das personagens que ela cria nessas fotos, e de recursos frequentes como fotomontagem, inversões e dupla exposição, as imagens se afastam do realismo e potencializam uma sensação de estranheza, flertando com o surrealismo, movimento em que Cahun militou ativamente na

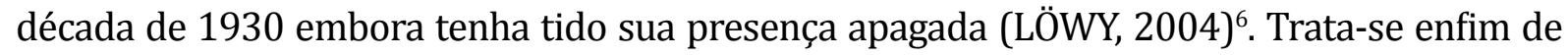
uma linguagem que não objetiva validar o reconhecimento imediato; ao contrário, emprestando novamente termos de Sontag, pode-se descrever as imagens de Cahun como a "criação de um mundo em duplicata, de uma realidade de segundo grau, mais rigorosa e mais dramática que aquela percebida pela visão natural" (SONTAG, [1977] 2004, p. 67).

Judia, antifascista e vinda de uma família esclarecida e abastada, Lucie/Claude era filha do editor Maurice Schwob e sobrinha do escritor simbolista Marcel Schwob. Desde cedo rejeitou normas e imposições sociais, assumindo-se lésbica e mantendo com a artista gráfica Suzanne Malherbe (1892-1972), também conhecida como Marcel Moore, um longo relacionamento que durou da adolescência (conheceram-se em 1909) até a morte de Claude, em 1954 (COLORADO-NATES, 2017).

Junto com sua parceira, Claude foi presa e condenada à morte pelo regime nazista, em 1944, e libertada, em 1945, pelas forças aliadas, uma experiência da qual nunca se recuperou completamente (SHAW, 2017). Esquecida depois de sua morte, em 1954, só foi redescoberta no fim da década de 1980, tendo tido, a partir daí, reconhecida sua importância no contexto cultural das primeiras décadas do século XX (ARVISAIS, 2015). Mais recentemente, tem sido referenciada como uma espécie de precursora da teoria queer, dada sua atuação pioneira, por meio de sua obra, na desconstrução do sistema binário masculino/feminino (LLABATA, 2014; BRUJEIRO, 2016; TORRES, 2016).

\footnotetext{
${ }^{6}$ Cahun manteve relações com Georges Bataille e André Breton, participando ativamente de encontros, produções e exposições de artistas surrealistas, embora, como outras artistas mulheres, tenha tido sua presença apagada no movimento. Como observa Michel Löwy, a artista "só recebeu menção em uma nota de rodapé na canônica Histoire du surréalisme (História do surrealismo), de Maurice Nadeau", e só muito recentemente vem sendo reconhecida como "única fotógrafa significativa do grupo surrealista" (LÖWY, 2004, p. 129).
} 


\section{Queer é Claude: traços identitários}

Segundo Brujeiro (2016), Claude Cahun foi apagada dos anais do Surrealismo, movimento em que militou ativamente, "um pouco por ser mulher, e outro tanto por ser uma verdadeira estranha entre os proclamados estranhos" (BRUJEIRO, 2016, p. 48). Com efeito, como observa Löwy, "frequentemente artistas são deslocados e transgressores, mas poucos deles incorporam tantas qualidades rompedoras de limites como Claude Cahun" (LÖWY, 2004, p. 129). Pode-se dizer que esse deslocamento, essa condição de "estranha" e transgressora da artista - da qual fazem parte sua própria orientação sexual e sua identidade de gênero - antecipam o sentido que, várias décadas depois, seria atribuído à ideia de queer.

A adoção do nome Claude Cahun deu-se em 1917, aos 22 anos de idade, combinando um prenome de gênero ambíguo com o sobrenome de sua avó materna. Com isto, como observa Arvisais (2015), a artista passou a integrar uma longa lista de mulheres, no século XIX e no início do XX, que publicaram com nomes que não o seu, muitas vezes masculinos. A prática era comum para facilitar a entrada nos campos literário e artístico, majoritariamente masculinos, servindo para disfarçar o gênero da artista por meio de uma identidade falsa. 0 caso de Claude Cahun, no entanto, é diferente: a máscara pseudomínica torna-se um meio de combinar ou sobrepor (e não de disfarçar) traços de identidade, subvertendo papéis sexuais e o conceito de uma identidade imutável (ARVISAIS, 2015, p. 181).

Brujeiro prossegue afirmando que o trabalho artístico de Cahun "bem poderia ter morrido com ela, mas foi o tempo quem encontrou os interlocutores e os marcos de referência adequados para essas obras que antecedem em mais de meio século os estudos de gênero e a teoria queer, tópicos próprios do século XXI pelos quais a artista incursionou praticamente um século antes" (BRUJEIRO, 2016, p. 48).

\section{Autorretratos, vestimenta e gênero: uma tentativa de análise}

A produção de autorretratos de Claude Cahun estendeu-se por um longo período, iniciando-se ainda na década de 1910. As imagens mostram a artista assumindo múltiplas personas - ora personagens aparentemente ficcionais, ora o que parecem ser faces de sua própria personalidade - que, em geral, têm em comum o fato de desafiar as fronteiras do masculino e do feminino.

Pouco se sabe sobre as motivações e as condições de produção dessas imagens, salvo por algumas indicações esparsas nos escritos da artista. "Sob esta máscara, outra máscara; eu nunca terminarei de remover todas essas caras"7, escreveu Cahun em uma montagem com fragmentos desses autorretratos, usada como ilustração em seu livro Aveux non avenues (figura 1), o que pode sugerir que se tratava de um projeto de longo prazo desenvolvido durante sua vida (ROTH, 2017). É possível supor que Marcel Moore tenha participado da produção, seja dirigindo Cahun, seja operando a câmera. Sobre isto não há informações muito precisas, mas a própria classificação das fotos como autorretratos é por vezes criticada (LATIMER, 2006; SMITH, 2008).

7 Tradução nossa para: "Sous ce masque un autre masque; je n'en finirai pas d'enlever tous ces visages". 


\section{FIGURA 1 - ILUSTRAÇÃO COM FRAGMENTOS DE AUTORRETRATOS USADA EM AVEUX NON AVENUES}

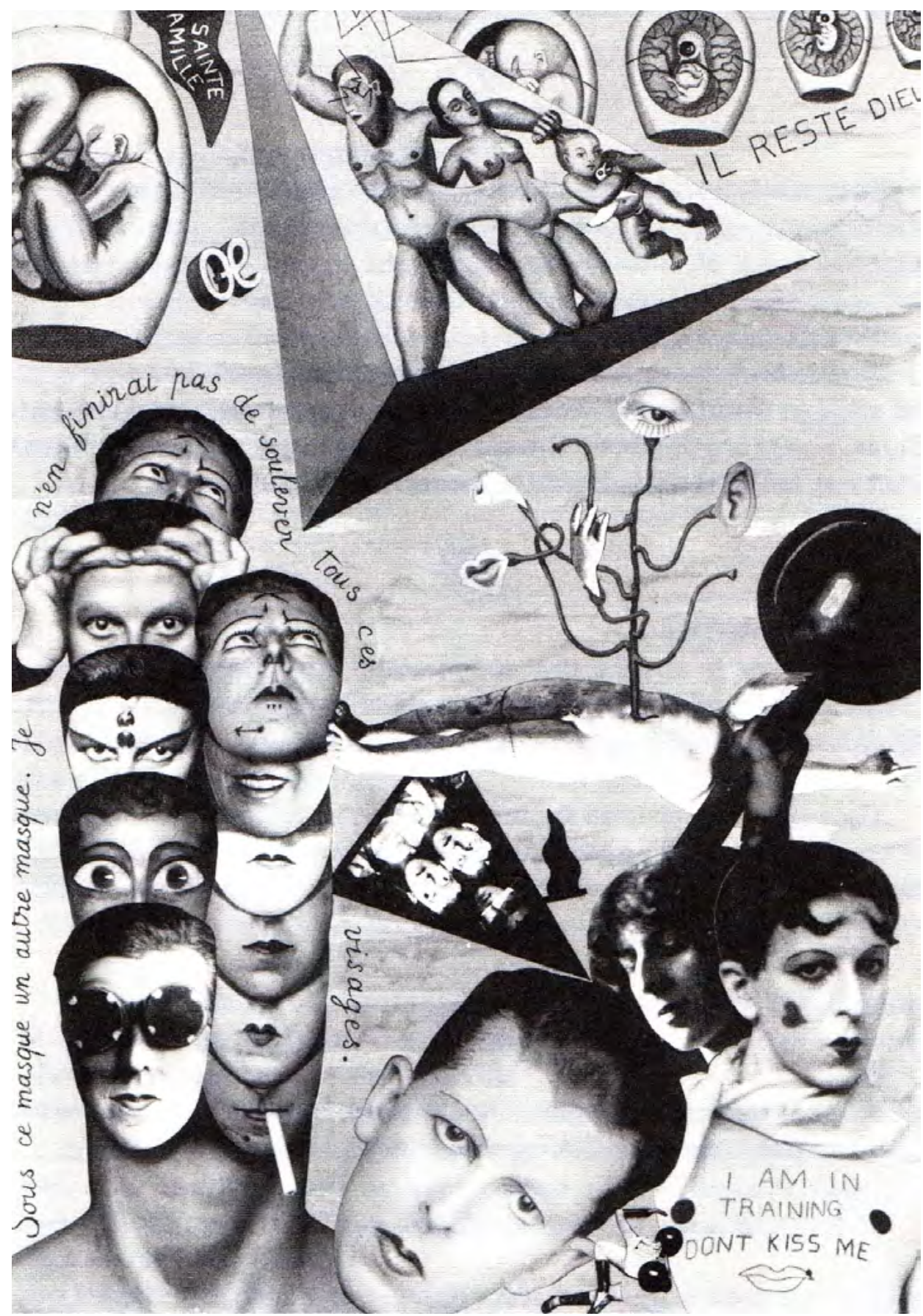

FONTE: CAHUN, Claude. Disavowals or cancelled confessions. ([1930] 2007, p. 183).

O que se sabe com segurança é que essa produção de autorretratos não foi publicada ou exibida pela artista em vida. Exceto por um único autorretrato, reproduzido em 1930 no número 5 da revista literária e artística Bifur (GAMBI, 2015), e por alguns fragmentos de imagens usados em colagens que ilustram o livro Aveux non avenues, como a da figura 1, não há registros de que os autorretratos de Cahun tenham circulado em publicações. Também não 
se tem notícia de que a artista tenha feito exposições dessas imagens (CUMMING, 2017), que acabaram permanecendo desconhecidas até décadas após sua morte. Para Solomon-Godeau (1999), Claude Cahun "optou por não exibir ou reproduzir a maior parte de suas imagens, mesmo sendo claro que sua produção exigia uma grande preparação, envolvendo trajes elaborados, maquiagem e iluminação" (SOLOMON-GODEAU, 1999, p. 116-117, grifo nosso).

Quanto aos trajes, a não ser por um número restrito de imagens em que a artista aparece nua ou seminua (figura 2), é impossível não reconhecer que eles - junto com outros itens de moda, como calçados, acessórios, penteados e maquiagem - têm uma função na composição das personas criadas nos autorretratos. Em geral, seu emprego ajuda a criar o caráter enigmático, ambíguo e incomum que a artista imprime a suas imagens (figuras 3 a 5).

FIGURA 2 - AUTORRETRATO DE CLAUDE CAHUN NUA (1930)

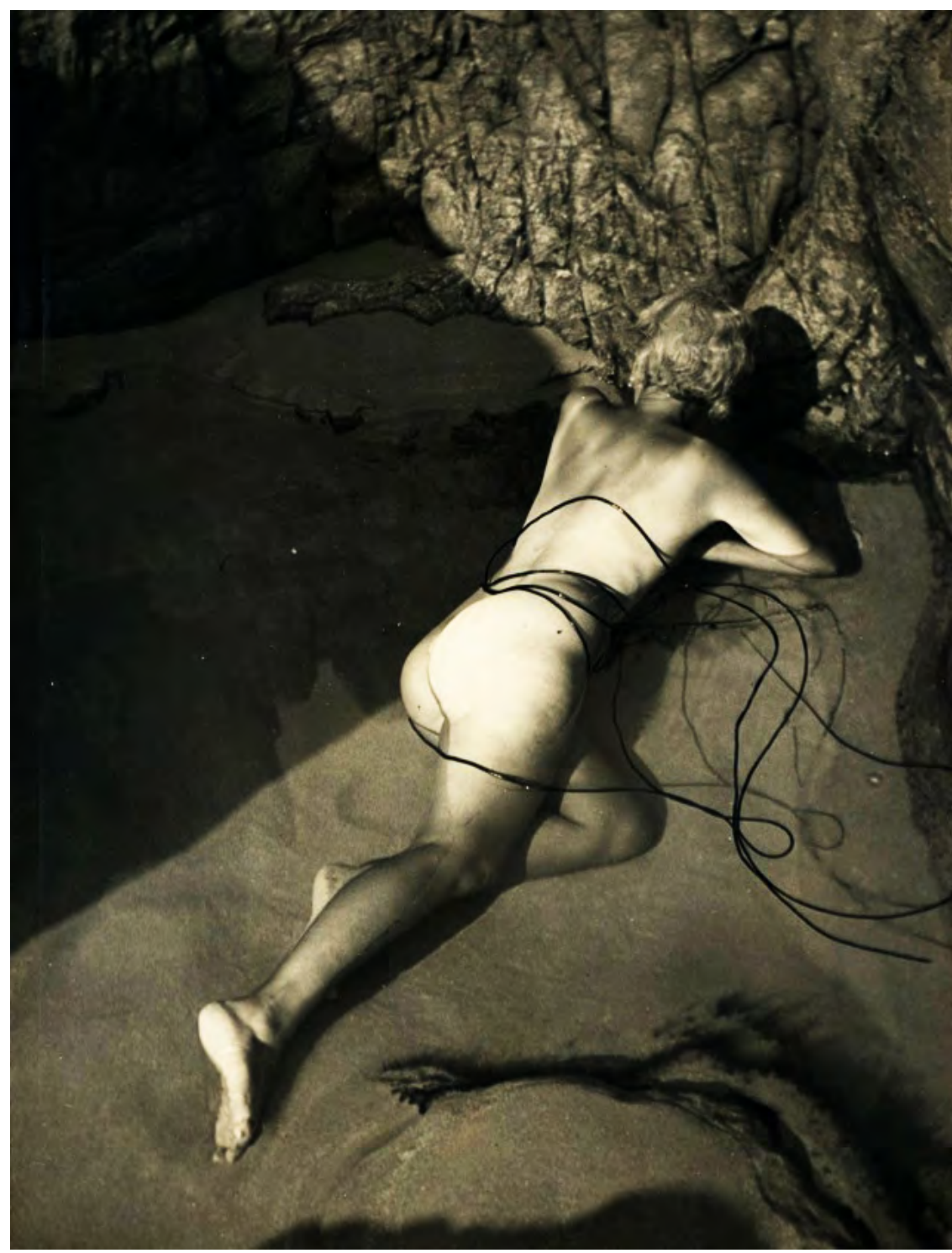

FONTE: Acervo Jersey Heritage. Disponível em: http://www.jerseyheritage.org/collection-items/claude-cahun. Acesso em: jun. 2019. 
Cabe, então, propormos uma discussão mais detalhada acerca do papel das vestimentas (e demais itens de moda) na criação das imagens de Cahun. A roupa é, para Letícia Lanz, "ao mesmo tempo, um operador de socialização, um mecanismo de controle social e um veículo de libertação da tirania dos condicionantes culturais" (LANZ, 2015, p. 173, grifo nosso). É neste terceiro aspecto que a vestimenta parece ter uma função no trabalho artístico de Cahun, como instrumento do que, décadas depois, Butler ([1990] 2017) chamará de práticas performativas de gênero. Ela parece servir ao questionamento, por parte de Cahun, das imposições sociais em relação à feminilidade, à masculinidade e ao binarismo de gênero. A própria artista, em sua obra semiautobiográfica Aveux non avenues, declara que o sentido de seu trabalho está em

\footnotetext{
Embaralhar as cartas. Masculino? Feminino? Mas isso depende dos casos. Neutro é o único gênero que sempre me convém. Se ele existisse na nossa língua, não se observaria essa flutuação do meu pensamento. Eu seria, seguramente, um bom exemplo dele. (CAHUN, [1930] 2007, p. 151-152)
}

A fim de encaminhar a discussão, verificando o papel da vestimenta nesse "embaralhamento" do gênero nos autorretratos de Cahun, selecionamos para análise um pequeno conjunto de três imagens representativas da obra da artista, em que sua aparência respectivamente pende para o feminino, para o masculino e fica a meio caminho. Essa análise é desenvolvida nos itens 3.1 a 3.3, a seguir.

A interpretação que propomos inspira-se no método iconográfico, proposto por Erwin Panofsky ([1955] 2011) para a leitura de imagens artísticas. Esse autor detalha três níveis de interpretação que devem ser percorridos para a apreensão do significado de uma determinada imagem: o primeiro e mais superficial é a descrição pré-iconográfica, que consiste em identificar da forma mais detalhada possível todos os objetos e/ou EvENTOS VIsíVEIS NA SUPERFICIALIDADE DA IMAGEM. BURKE ([2001] 2004) exemplifica: objeto pode ser uma árvore, um prédio, um animal, um conjunto de pessoas; evento pode ser uma refeição, uma batalha, uma procissão etc.

O segundo nível é a análise iconográfica, em que o pesquisador relaciona os elementos pré-iconográficos identificados no nível anterior a assuntos ou conceitos de seu conhecimento prévio. Burke prossegue com o exemplo: trata-se aqui de reconhecer uma refeição como a Última Ceia, ou uma batalha como a Batalha de Waterloo, e assim por diante.

O terceiro e mais profundo é a análise iconológica, voltada à interpretação das circunstâncias que condicionaram a produção da imagem e que permitem sua leitura além da superficialidade, apreendendo seu "sentido intrínseco" - em última análise, o que ela "significa".

Como observa Burke (2004), esses três níveis de análise pictórica são análogos aos três níveis propostos pelo filólogo e filósofo alemão Friedrich Ast (1778-1841) para a hermenêutica, 
arte da interpretação de textos: o nível literal ou gramatical, o nível histórico e o nível cultural, este último voltado para captar o "espírito" (geist) presente no texto (BURKE, 2004, p. 45). Nesse sentido, o método de Panofsky pode ser visto como uma adaptação para as imagens de uma tradição alemã de interpretação de textos. Ao longo dos três níveis de análise, o trabalho passa de meramente descritivo para essencialmente interpretativo, ao mesmo tempo que se exige do analista um conhecimento contextual a respeito do ambiente (histórico, social, cultural) que engendra a imagem analisada, sem o qual a interpretação fica prejudicada.

Kossoy (1999), ao adaptar a proposta de Panofsky especificamente para a análise de imagens fotográficas, considerará que os dois primeiros níveis correspondem à apreensão da chamada "segunda realidade" (exterior ao fotógrafo, capturada e congelada pelo clique, contida nos limites bidimensionais da imagem), ao passo que o terceiro visa aproximar a "primeira realidade", invisível na foto por ser interior ao fotógrafo, relacionada à intencionalidade, às circunstâncias e às condições de produção da imagem. Para Kossoy, "toda e qualquer imagem fotográfica contém em si, oculta e internamente, uma história: é a sua realidade interior, abrangente e complexa, invisível fotograficamente e inacessível fisicamente" (KOSSOY, 1999, p. 36).

Capturar essa "história" em três imagens de Claude Cahun, portanto, é o que nos propomos fazer a seguir.

\section{Uma persona feminina: a heroína sem peitos}

Um dos autorretratos hoje mais conhecidos de Claude Cahun, datado de 1929 (figura 3), nos apresenta uma personagem feminina. Sua data de produção é alguns anos posterior à da publicação do livro Héroïnes (1925), e a personagem em questão é ela própria uma heroína de conto de fadas: a mulher de Barba Azul, personagem do conto homônimo de Charles Perrault (SMITH, 2008).

Em uma descrição pré-iconográfica, primeiro nível de interpretação segundo Panofsky, boa parte dos elementos que nos chamam a atenção são itens de vestuário e moda: o penteado com tranças, a maquiagem no rosto, os sapatos fechados e, principalmente, o pesado vestido que ocupa grande parte da superfície da foto, destacando-se sobre o fundo escuro. Ainda nesse primeiro nível de análise, certas características do corpo da personagem sobressaem de imediato: ele está curvado, quase retorcido, e seus braços não são visíveis, recolhidos detrás do tronco. Um último elemento chama a atenção mais por sua falta do que por sua presença: a personagem tem o torso reto, isto é, parece não ter seios. 


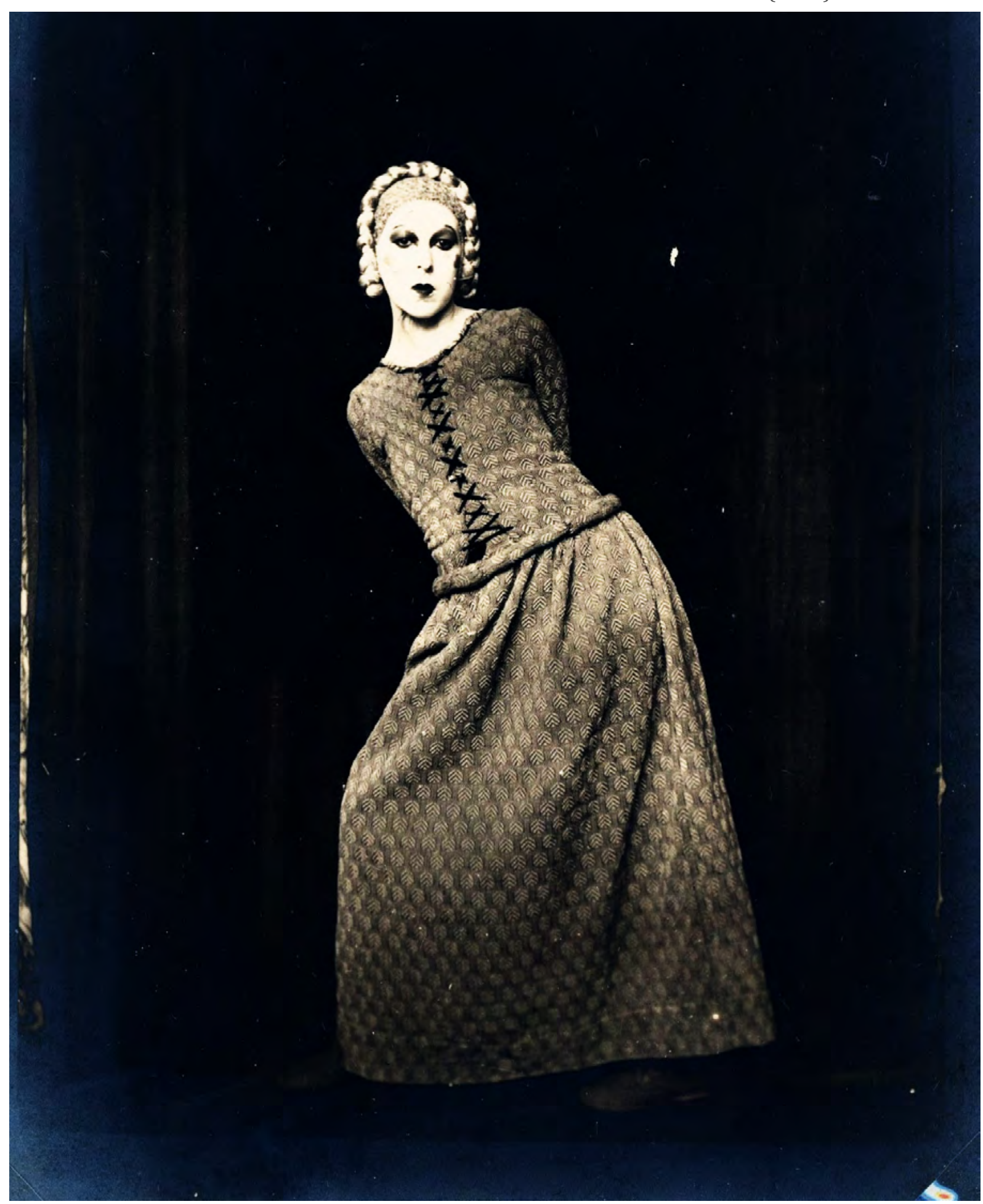

FONTE: Acervo Jersey Heritage. Disponível em: http://www.jerseyheritage.org/collection-items/claude-cahun. Acesso em: jun. 2019. 
De posse dessa descrição pré-iconográfica, passamos ao nível seguinte: a análise iconográfica. É aqui que, associando os elementos anteriormente observados ao nosso repertório prévio, reconhecemos o gênero performado pela figura da foto: ele é inequivocamente feminino. A roupa, o penteado, o rosto maquiado e o batom marcante não nos deixam margem para outra interpretação. Decerto é uma mulher que pode causar alguma estranheza, mas ainda assim com gênero feminino bastante inteligível a partir da matriz binária convencional. Podemos supor que a artista tenha comprimido os seios com uma faixa sob o vestido, para compor a personagem. Para além da ausência de seios, a posição retorcida da personagem é claramente desconfortável e os braços dão a impressão de estarem atados, limitando os movimentos.

No terceiro nível (análise iconológica), aquilo que no segundo causou estranheza - o corpo retorcido, os braços aparentemente atados, a ausência de seios - pode nos revelar algo sobre o que significa a imagem em uma camada de interpretação mais profunda (nos termos de Panofsky), ou sobre a "história" que jaz detrás dela (na expressão de Kossoy). 0 tórax parece de fato deslocado nessa figura, que em tantos outros elementos ostenta signos femininos. 0 deslocamento, o desconforto e a angustiante sensação de limitação experimentados pela personagem podem ser, em uma interpretação cabível, os mesmos que a própria Claude Cahun experimentaria em relação ao seu gênero "de nascença".

\section{Uma persona masculina: o dândi}

Na segunda imagem analisada (figura 4), mais uma vez os itens de vestuário são os que mais chamam a atenção no primeiro nível de interpretação, pré-iconográfico: calça e paletó escuros, foulard em tom claro (supõe-se que seja branco) encobrindo o colarinho da camisa na mesma cor, lenço de bolso. 0 personagem que os usa está em pé, em posição relaxada, e ostenta a cabeça raspada ou os cabelos extremamente curtos, a ponto de não serem claramente visíveis na foto. Ao contrário do observado na figura anterior, não há nenhum tipo de maquiagem aparente. A mão direita do personagem encontra-se delicadamente apoiada na cintura e, entre os dedos anelar e mínimo, é possível distinguir um cigarro ainda apagado. 0 braço direito pende sem apoio junto ao corpo e a mão correspondente está fechada. 0 fundo da imagem (uma peça retangular monocromática de pano ou tapeçaria sobre parede mais clara) é relativamente neutro, destacando-se pouco em relação ao personagem. 


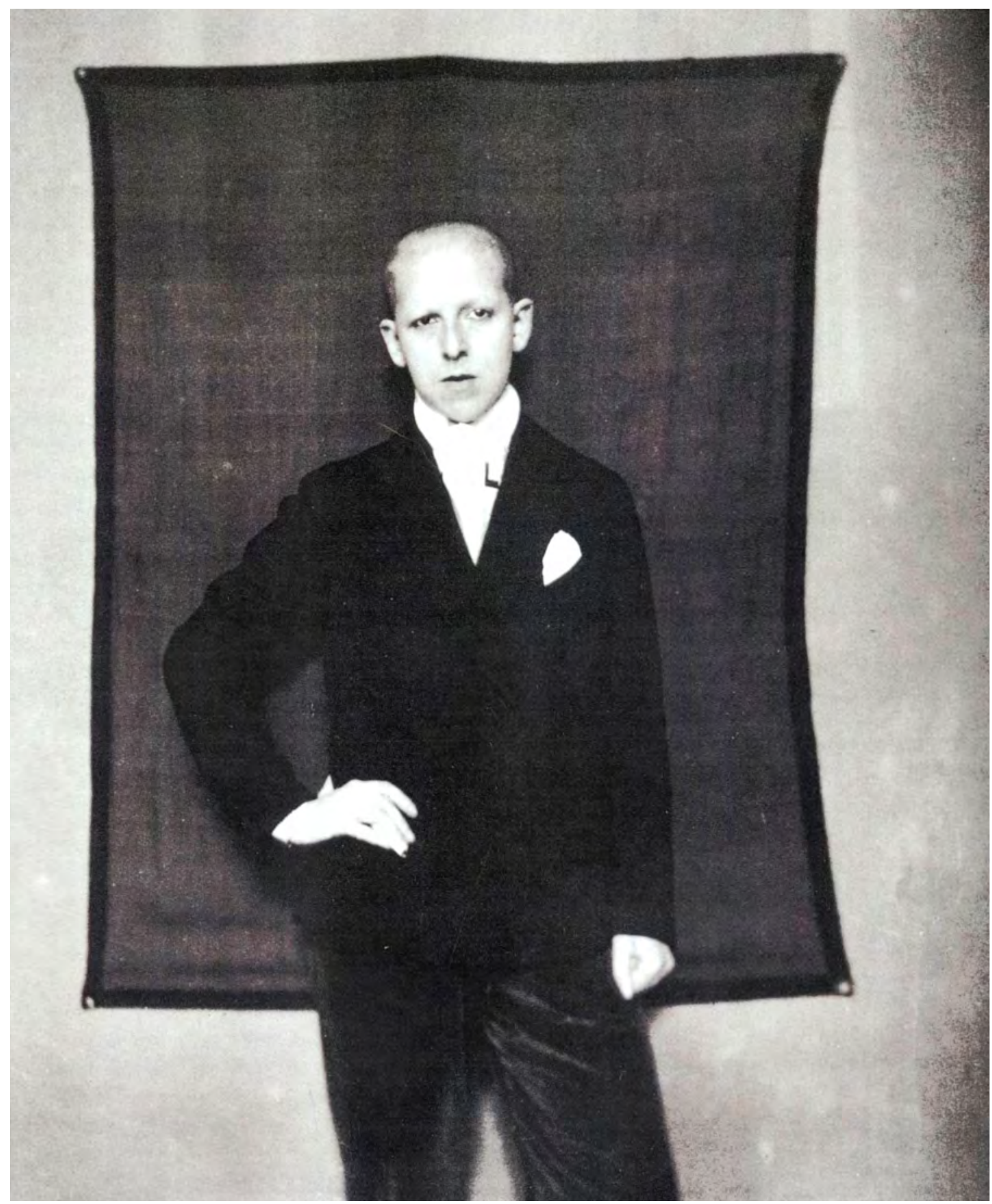

FONTE: Acervo Jersey Heritage. Disponível em: http://www.jerseyheritage.org/collection-items/claude-cahun. Acesso em: jun. 2019. 
No nível seguinte, iconográfico, novamente reconhecemos o gênero do personagem. Ele é inequivocamente masculino e, assim como no exemplo anterior, são as roupas (junto com demais itens de moda, como o corte de cabelo e a ausência de maquiagem) que nos fornecem os elementos para essa conclusão. Mas podemos prosseguir a análise iconográfica associando o personagem a uma categoria específica de homem: o dândi, termo que designa um homem excêntrico e de aguçada preocupação estética, "que valoriza o refinamento em seu modo de viver, aí incluída a moda" (MENESES, 2019, p. 35). Na imagem analisada, a delicadeza dos gestos e o refinamento dos trajes conduzem a essa associação.

Por fim, na análise iconológica, lembremos que um dândi caracteriza-se não só pela excentricidade e refinamento no vestir (ECHAVARREN, 2010), mas também pela atitude contestatória. Para Miròn (2015), os dândis "querem ser ou se imaginam singulares, e pretendem afirmar-se pela atitude e aparência" (MIRÒN, 2015, p. 44), e com frequência essa atitude desafia as formas de expressar masculinidade, passando por um "parecer masculino e feminino ao mesmo tempo" (MIRÒN, 2015, p. 42). Eis a masculinidade contra-hegemônica que encontramos performada nesse personagem masculino de Claude Cahun: uma masculinidade dândi, contestadora e ambígua, que flerta com a efeminação e as fronteirAS DE GÊNERO.

\section{Uma persona ambígua: o/a halterofilista}

Na terceira imagem analisada (figura 5), a descrição pré-iconográfica nos revela uma figura sentada de pernas cruzadas, vestindo calção escuro e lenços ao redor da cintura e do pescoço. A indumentária é completada por collant claro ajustado ao corpo e por uma calça-ceroula que cobre suas pernas, feita do mesmo material e com a mesma cor, o que sugere tratar-se de uma peça única, apenas coberta pelo calção. A cor da peça é clara (próxima à da pele da personagem), e ela ostenta uma inscrição em inglês (I am in training, don't kiss me), além de desenhos de bocas e corações e dois pequenos apliques circulares na altura dos mamilos. A personagem tem cabelos curtos, porém dois cachos encaracolados caem sobre seu rosto, caricaturalmente maquiado. Completando a descrição pré-iconográfica, a personagem segura uma barra de pesos, em que se distingue mais um texto: Totor et Popol. 


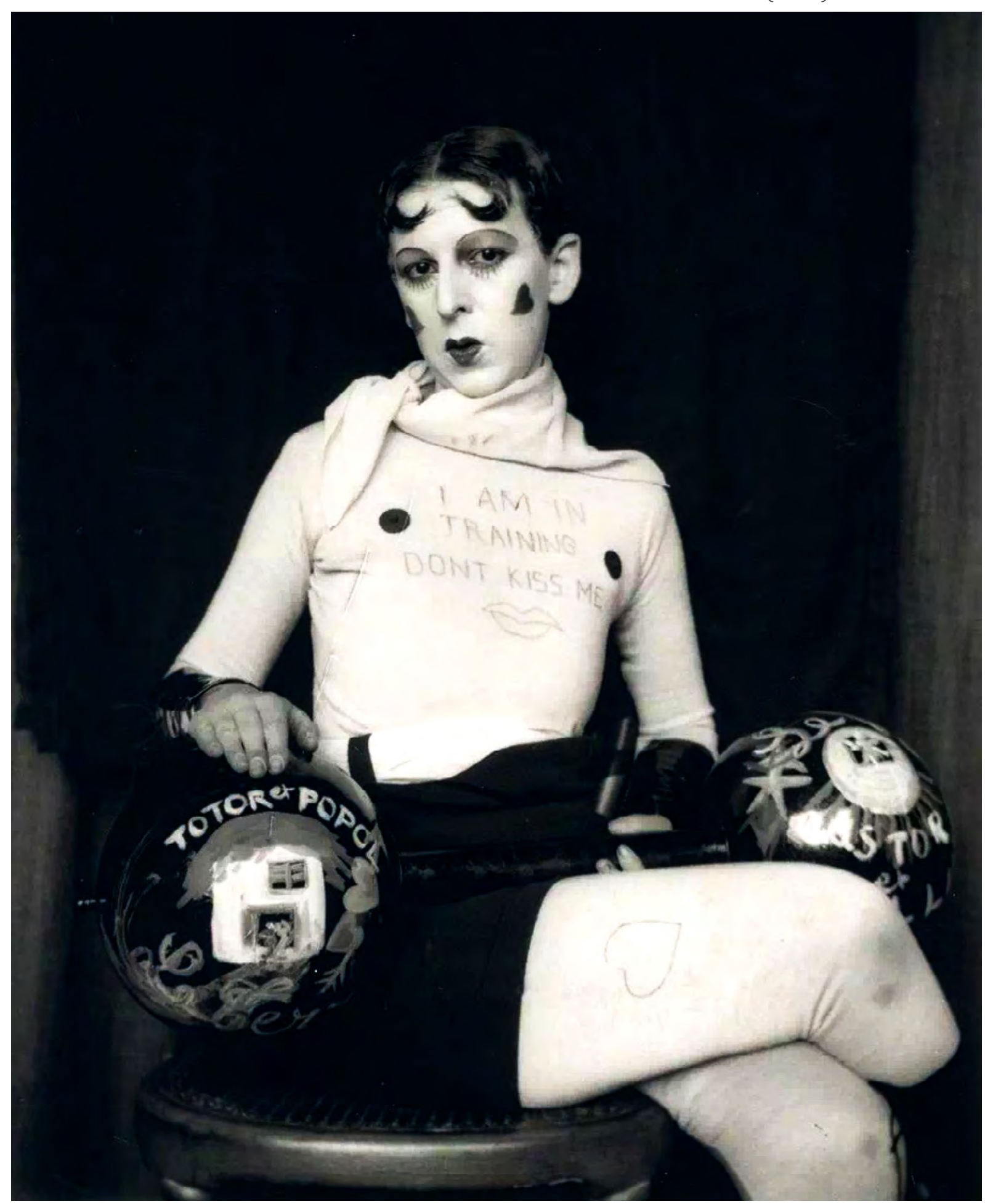

FONTE: Acervo Jersey Heritage. Disponível em: http://www.jerseyheritage.org/collection-items/claude-cahun. Acesso em: jun. 2019. 
No segundo nível, diferentemente do ocorrido com as duas imagens anteriores, resulta difícil reconhecer de imediato o gênero da personagem levando em conta a escala binária. De um lado, alguns signos são de virilidade: estaria ali representado um homem de calção, sem camisa, peito à mostra, corpo tatuado, praticante de halterofilismo. De outro, o modo de cruzar as pernas, a languidez do olhar e diversos elementos do rosto (penteado, maquiagem, lábios pintados) são signos de hiperfeminilidade. Esse contraste de estereótipos produz um efeito de estranheza e ao mesmo tempo de comicidade. A boca estereotipadamente feminina convida ao beijo, mas a tatuagem no tórax viril o repele: don't kiss me. A comicidade é reforçada pela referência a Totor e Popol, personagens cômicos de quadrinhos do cartunista belga Hergé (que, posteriormente, se tornaria mais conhecido pelo personagem Tintin).

Chegamos assim à análise iconológica dessa terceira imagem, identificando por fim o sentido intrínseco, isto é, a "história" ou "primeira realidade" (KOSSOY, 1999) contida em seu interior. 0 personagem está "in training", em treinamento, o que convida a diferentes leituras: o treino esportivo do (ou da) atleta, mas, também, um exercício de experimentação da artista em busca da sua própria identidade, que a leva a um constante trocar de máscaras, como na figura 1. Por meio da foto, Cahun debocha do padrão binário e dos estereótipos de gênero impostos por uma sociedade para a qual "as pessoas só se tornam inteligíveis ao adquirir seu gênero em conformidade com os padrões reconhecíveis de inteligibilidade" (BUTLER, [1990] 2017, p. 42). Com humor, ela "embaralha as cartas" (CAHUN, [1930] 2007, p. 151) e indica outras possibilidades performativas que rompem a fronteira dos gêneros binários, e que ela própria está experimentando (training) em sua vida. Queer avant la lettre, Cahun antecipa em várias décadas um debate que seria trazido à tona pelos estudos de gênero e pela teoria queer.

\section{Considerações finais}

A análise empreendida forneceu-nos alguns elementos para responder a questão do artigo: pudemos ver quão central é o papel performativo que a vestimenta (e demais itens de moda) exerce no trabalho artístico de Claude Cahun.

Isto pode ser ilustrado a partir dos três exemplos analisados. A "heroína" da figura 3, como vimos, tem sua inteligibilidade feminina garantida pelo vestido, pelo penteado e pela maquiagem do rosto, que a caracterizam convincentemente como mulher, com força suficiente para fazer-nos relevar a ausência de seios. De modo semelhante, o homem da figura 4 também é passível de ser reconhecido como tal graças, predominantemente, ou exclusivamente, a elementos de moda. A personagem ambígua da figura 5, por fim, diverte-se em confundir-nos ao emitir sinais embaralhados também por meio do seu uso de moda. Nos três casos analisados, é no corpo vestido, nos signos a ele conferidos por itens de moda, que encontramos elementos para entender em que polo cada personagem performa: se no feminino, se no masculino, se na mescla transgressora de ambos. É, enfim, na roupa das personagens de Claude Cahun que encontramos um meio para o reconhecimento de identidades de gênero, classificando-as, com diferentes graus de dificuldade, de acordo com as categorias da matriz binária. 
Uma segunda consideração é que os autorretratos parecem corroborar as argumentações de que a obra de Cahun refletiria a necessidade interior da própria artista de experimentar ou encontrar sua própria identidade. Isto se verifica mesmo nas personas de Cahun que operam na matriz de inteligibilidade binária: a mulher sem seios da figura 2 transmite uma boa dose de deslocamento e desconforto ao performar seu gênero feminino, e o homem da figura 3 carrega uma masculinidade dândi, contestadora e ambígua, flertando com a efeminação. Ambos sugerem questionamentos em relação à matriz normativa binária. Vemos aqui antecipada em várias décadas uma discussão que seria desenvolvida a partir dos anos 1980 com o surgimento da teoria queer: a de que gêneros e identidades sexuais não são biologicamente inscritos na natureza humana, mas sim resultado de construção social, e a classificação dos gêneros em duas categorias binárias fixas - masculino e feminino - desconsidera e marginaliza uma variedade de outras identidades e papéis sexuais.

Por outro lado, este trabalho certamente apresenta limitações. Temos ciência, por exemplo, de que o método iconográfico que optamos por utilizar é por vezes criticado - sobretudo, como nos lembra Burke (2004), por ser demasiadamente intuitivo e especulativo. Além disso, o mesmo autor também observa que o método de Panofsky pode demandar adaptações quando usado especificamente para lidar com imagens de artistas surrealistas, uma vez que estes artistas "rejeitavam a ideia de um programa coerente e buscavam, em vez disso, expressar as ações da mente inconsciente" (BURKE, 2004, p. 51-52). Isto sugere que, para ser usado com mais propriedade, o método deva ser complementado com outras ferramentas - como, por exemplo, as da psicanálise, como proposto por Ide (2017) -, que podem conferir-lhe mais potência a fim da captar o "significado" da imagem, na terminologia usada por Panofsky, ou a "primeira realidade" de que fala Kossoy.

Outra limitação do trabalho está no fato de termos feito uma incursão ainda bastante inicial na obra de Claude Cahun ao nos restringirmos à análise de apenas três fotos pinçadas da obra da artista. Há um vasto número de imagens que ainda merecem ser estudadas, o que não coube no escopo do artigo.

Por outro lado, acreditamos que a originalidade deste trabalho está no fato de não haver, até onde nos foi possível avaliar, outros trabalhos, especificamente na área da Moda, que tenham pesquisado a obra de Claude Cahun. Nesse sentido, as considerações que fazemos aqui, mais do que conclusões, podem ser lidas como sugestões para aprofundamento em trabalhos futuros. 


\section{Referências}

ARVISAIS, Alexandra. Détournement du savoir féminin dans les écrits journalistiques de Claude Cahun alias « M ». @analyses - Revue de Critique et de Théorie Littéraire, v. 10, n. 1, 2015. Disponível em: https://doi.org/10.18192/analyses.v10i1.1243. Acesso em: 29 jun. 2019.

BRUJEIRO, Verónica. Claude Cahun: la máscara como nombre propio. Casa del Tiempo, México, v. 3, n. 33, 2016, p. 47-51.

BURKE, Peter. Testemunha ocular: o uso de imagens como evidência histórica. Bauru: EDUSC, 2004.

BUTLER, Judith. Problemas de gênero: feminismo e subversão da identidade. Rio de Janeiro: Civilização Brasileira, 2017.

CAHUN, Claude. Heroínas, 1925. Tradução Daniel Lühmann. Rio de Janeiro: A Bolha Editora, 2016.

CAHUN, Claude. Disavowals or cancelled confessions, 1930. Tradução Susan de Muth. Cambridge: The MIT Press, 2007.

COLORADO NATES, Óscar. Claude Cahun y la exploración de la identidad. Óscar en Fotos. 6 mai 2017. Disponível em: https://oscarenfotos.com/2017/05/06/claude-cahun-y-laexploracion-de-la-identidad/. Acesso em: 29 jun. 2019.

CUMMING, Laura. Gillian Wearing and Claude Cahun: behind the mask, another mask review. The Observer. 12 mar. 2017. Disponível em: https://www.theguardian.com/ artanddesign/2017/mar/12/gillian-wearing-and-claude-cahun-behind-the-mask-reviewnational-portrait-gallery. Acesso em: 29 jun. 2019.

ECHAVARREN, Roberto. Arte andrógino: estilo vs moda. Montevidéu: Hum, 2010.

GAMBI, Henrique do Nascimento. Entre o inconfessável e o indizível: autobiografia e autorretrato em Aveux non Avenues, de Claude Cahun. 2015. 182 f. Tese (Doutorado em Estudos Literários) - Faculdade de Letras, Universidade Federal de Minas Gerais, Belo Horizonte, 2015.

IDE, Danilo Sergio. Uma iconologia instigada pela arte interpretativa dos sonhos de Freud. Revista de Psicologia, Fortaleza, v. 8, n. 1, 2017, p. 129-240.

KOSSOY, Boris. Realidades e ficções na trama fotográfica. Cotia: Ateliê Editorial, 1999. 
LANZ, Letícia. 0 corpo da roupa. São Paulo: Editora Transgente, 2015.

LATIMER, Tirza True. Entre bous: between Claude Cahun and Marcel Moore. GLQ: A Journal of Lesbian and Gay Studies, v. 12, n. 2, 2006, p. 197-216.

LEPERLIER, François. Claude Cahun: l'exotisme intérieur. Paris: Fayard, 2006.

LLABATA, Carmen Senabre. Claude Cahun: el tercer sexo o la/s identidad/es al desnudo. Dossiers Feministas, Castellón de la Plana, v. 28, 2014, p. 79-92.

LÖWY, Michael. Una surrealista desconocida. New Left Review, Madri, v. 29, 2004, p. 129135.

MENESES, Emerson Silva. Quem é esse rapaz que tanto androginiza? Transgressões vestimentares nas homossexualidades não-hegemônicas. 2019.147 f. Dissertação (Mestrado em Têxtil e Moda) - Escola de Artes, Ciências e Humanidades, Universidade de São Paulo, São Paulo, 2019.

MIRÒN, Andreia. Dândi: corpo e moda masculina. São Paulo: Scortecci, 2015.

PANOFSKY, Erwin. Significado nas artes visuais. São Paulo: Perspectiva, 2011.

ROTH, Zoë. Frontière humaine: race, nation, and the shape of representation in Claude Cahun. In: Gelber, Mark H.; Sjöeberg, Sami (Eds.). Jewish aspects in avant-garde: between rebellion and revelation. Berlim: Walter de Gryyter, 2017.

SHAW, Jennifer L. Exist otherwise: the life and works of Claude Cahun. Londres: Reaktion Books, 2017.

SMITH, Amber. Upping the anti in Claude Cahun and Marcel Moore's collaborative 'self portraits'.2008. 104 f. Dissertação (Mestrado em Artes) - Graduate School of the State University of New York at Buffalo, Buffalo, 2008.

SOLOMON-GODEAU, Abigail. The equivocal 'I': Claude Cahun as a lesbian subject. In: Rice, Shelley. Inverted Odisseys: Claude Cahun, Maya Deren, Cindy Sherman. Cambridge: The MIT Press, 1999.

SONTAG, Susan. Sobre fotografia. São Paulo: Cia. das Letras, 2004.

TORRES, Bolívar. Surrealista que desafiou convenções, Claude Cahun é lançada no Brasil 62 anos após sua morte. 0 Globo. 3/12/2016. Disponível em: https://oglobo.globo.com/ cultura/livros/surrealista-que-desafiou-convencoes-claude-cahun-lancada-no-brasil-62anos-apos-sua-morte-20580548. Acesso em: 29 jun. 2019. 